Letter

\section{Neurological diseases and risk of mortality in patients with COVID-19 and SARS: a territory- wide study in Hong Kong}

\section{INTRODUCTION}

COVID-19 is caused by $ß$-coronavirus SARS-CoV-2. Recent reports suggested that neurological diseases, in particular stroke, dementia and advanced Parkinson's disease (PD), were important predictors of COVID-19-related mortality. ${ }^{1-3}$ SARS-CoV was another $ß$-coronavirus which resulted in the epidemic of SARS in late 2002 to early 2003. Apparently, it remained quiescent since 2004 but its re-emergence is possible. Patients with SARS at advanced age and with multiple comorbidities were at higher risk of mortality. ${ }^{4}$

Given mortality rates and predictors may vary with regions, we investigated the impact of pre-existing neurological diseases on the mortality of patients with COVID-19 and SARS in Hong Kong, one of the most densely populated cities in the world. Studying the impact of neurological diseases on COVID-19 and SARS mortalities would have important implications on possible future pandemics caused by coronaviruses. We believe the data would provide guidance on resource allocation and healthcare policy making. With the availability of effective vaccination against COVID-19, the finding could implicate on the prioritisation of vaccination for patients with chronic neurological diseases.

\section{METHODS}

Study design and data retrieval

We performed a territory-wide retrospective cohort study using data from the Clinical Data Analysis and Reporting System (CDARS) under the management of the Hospital Authority, Hong Kong. CDARS is an electronic healthcare database that covers the patients' demographic, death, diagnoses, procedures, drug prescription and dispensing history, and laboratory results from all public hospitals and clinics in Hong Kong. It represents in-patient data of about $80 \%-90 \%$ of the 7.49 million population in Hong Kong. All confirmed patients with COVID-19 and SARS were reported to the Department of Health and hospitalised in public hospitals in Hong Kong. Patients were anonymised in CDARS to ensure confidentiality.

\section{Subjects}

Consecutive patients with laboratoryconfirmed COVID-19 from 23 January 2020 to 31 July 2020 and patients with SARS from March to June 2003 were identified by International Classification of Diseases, Ninth Revision, Clinical Modification (ICD-9-CM) diagnosis codes and/ or virological results (online supplemental table 1). Comorbidities data were defined and retrieved using ICD-9-CM coding (online supplemental table 2).

\section{Data collection and definitions}

Data were retrieved from CDARS in October 2020. The primary endpoint was death.

\section{Statistical analysis}

Data were analysed using SPSS V.25.0 (SPSS) and R software (V.4.0.3; R Foundation for Statistical Computing, Vienna, Austria). HRs and adjusted HRs (aHRs) with $95 \% \mathrm{CI}$ of neurological diseases on the incidence of mortality were estimated by Cox proportional hazards regression. All statistical tests were two-sided. Statistical significance was taken as $\mathrm{p}<0.05$.

\section{RESULTS}

A total of 3164 patients with COVID-19 were identified during the period of 23 January 2020-31 July 2020 and 1670 patients with SARS $(95.2 \%$ of all SARS cases) were identified during March-June 2003. The overall case fatality rates of COVID-19 and SARS in the studied period were $2.28 \%$ and $16.8 \%$, respectively.

Univariate and multivariable analysis of comorbidities associated with mortality among patients with COVID-19 and SARS.

On multivariable analysis among patients with COVID-19, stroke (aHR 2.31, 95\% CI 1.35 to $3.96, p=0.002)$ emerged as the third most outstanding predictors of mortality, after advancing age and renal diseases (aHR 2.68, 95\% CI 1.62 to 4.44, $\mathrm{p}<0.001)$. On multivariable analysis among patients with SARS, PD was the second strongest predictor of death (aHR $1.95,95 \% \mathrm{CI} 1.05$ to $3.64, \mathrm{p}=0.035$ ) after advancing age (see table 1).

\section{DISCUSSION}

Our study showed a strong association between stroke and COVID-19-related mortality that was reported in studies in other regions. ${ }^{12}$ In addition, we showed for the first time that PD was strongly associated with SARS-related mortality. Taken together, our study highlighted the vulnerability of patients having various pre-existing neurological diseases amid outbreaks of severe $ß$-coronavirus infection.

We speculated that the strong association between neurological diseases and mortality observed in our two separate cohorts may be due to the fact that patients with neurological disability often require assistance from caregivers in performing their daily activities, hence physical distancing in COVID-19 pandemic may not be feasible for them. The long duration of exposure with potential infected caregivers may confer a higher viral load to these patients, leading to a higher mortality. Moreover, infected patients with neurological disabilities, especially those of older age, may have non-specific symptoms or they are less capable in expressing their discomforts, leading to a delay in diagnosis and management, resulting in a higher mortality. Institutionalisation was believed to be a risk factor for COVID-19 infection and mortality. Note however in our COVID-19 cohort, stroke was associated with mortality independent of 'institutional living', suggesting that stroke per se was an important predictor of mortality. Both SARS-CoV and SARS-CoV-2 infections induce significant immune and inflammatory responses, and the resultant cytokine storm was believed to be responsible for causing the morbidity and mortality in susceptible hosts. The background neuroinflammation occurring in patients with chronic neurological diseases could be exacerbated by the inflammatory response and cytokine storm induced by the coronavirus infection, accounting for their association of worse outcomes.

The difference in association of neurological diseases and COVID-19 and SARS mortalities was intriguing. It was known that although SARS-CoV-2 and SARS-CoV are both $B$-coronaviruses and share $79 \%$ genome sequence identity with SARS-CoV, the two closely related viruses do differ in some ways. ${ }^{5}$ For example, the receptor binding motif (RBM) of SARSCoV-2 differed from that of SARS-CoV by five residues. Another four-residue motif in the RBM of SARS-CoV-2 confers better contact of the virus with the ACE receptor. These two differences between SARSCoV-2 and SARS-CoV allow the former to 
Table 1 Univariate and multivariable analysis with Cox proportional hazards model on factors associated with mortality in patients with COVID-19 and SARS

\begin{tabular}{|c|c|c|c|c|}
\hline \multirow[b]{2}{*}{ Parameters } & \multicolumn{2}{|l|}{ Univariate analysis } & \multicolumn{2}{|l|}{ Multivariable analysis } \\
\hline & $\mathrm{HR}(95 \% \mathrm{Cl})$ & $P$ value & aHR $(95 \% \mathrm{Cl})$ & $P$ value \\
\hline \multicolumn{5}{|l|}{ COVID-19 } \\
\hline \multicolumn{5}{|l|}{ Age (years) } \\
\hline$<60$ & Referent & & Referent & \\
\hline $60-69$ & 17.33 (3.60 to 83.42) & $<0.001$ & 14.75 (3.06 to 71.16$)$ & 0.001 \\
\hline $70-79$ & 84.69 (19.70 to 364.15$)$ & $<0.001$ & 54.61 (12.48 to 238.86$)$ & $<0.001$ \\
\hline 80 & 281.05 (67.99 to 1161.83 ) & $<0.001$ & 162.55 (38.26 to 690.67 ) & $<0.001$ \\
\hline Male sex & $1.30(0.81$ to 2.08$)$ & 0.279 & & \\
\hline Living in aged home & 11.90 (7.26 to 19.49$)$ & $<0.001$ & & \\
\hline Cardiovascular diseases & 23.15 (10.60 to 50.53$)$ & $<0.001$ & & \\
\hline Respiratory diseases & 2.66 (1.40 to 5.07$)$ & 0.003 & & \\
\hline Gastrointestinal diseases & 4.88 (3.01 to 7.91$)$ & $<0.001$ & & \\
\hline Hepatobiliary diseases & $1.61(0.83$ to 3.14$)$ & 0.162 & & \\
\hline Renal diseases & 10.27 (6.15 to 17.13$)$ & $<0.001$ & 2.68 (1.62 to 4.44$)$ & $<0.001$ \\
\hline Genitourinary diseases & 5.71 (3.40 to 9.60$)$ & $<0.001$ & & \\
\hline \multicolumn{5}{|l|}{ Neurological diseases } \\
\hline Stroke & 12.13 (7.28 to 20.20$)$ & $<0.001$ & 2.31 (1.35 to 3.96$)$ & 0.002 \\
\hline Dementia & 11.43 (5.97 to 21.89$)$ & $<0.001$ & & \\
\hline Parkinson's disease & Not available* & - & & \\
\hline Spine problems & 3.53 (1.42 to 8.76$)$ & 0.007 & & \\
\hline $\begin{array}{l}\text { Traumatic brain injury related } \\
\text { disorders }\end{array}$ & 3.08 (1.62 to 5.86$)$ & 0.001 & 1.86 (1.02 to 3.41$)$ & 0.043 \\
\hline Other neurological diseasest & 1.49 (0.60 to 3.69$)$ & 0.392 & & \\
\hline Diabetes mellitus & 7.67 (4.74 to 12.42$)$ & $<0.001$ & & \\
\hline Hyperlipidaemia & 7.74 (4.78 to 12.54$)$ & $<0.001$ & & \\
\hline Malignancies & 6.43 (3.59 to 11.53$)$ & $<0.001$ & 1.86 (1.02 to 3.41$)$ & 0.043 \\
\hline $\begin{array}{l}\text { Coexisting infection other than } \\
\text { COVID-19 }\end{array}$ & 3.89 (2.32 to 6.52$)$ & $<0.001$ & & \\
\hline \multicolumn{5}{|l|}{ SARS } \\
\hline \multicolumn{5}{|l|}{ Age (years) } \\
\hline$<60$ & Referent & & & \\
\hline $60-69$ & 3.51 (2.44 to 5.06$)$ & $<0.001$ & 2.05 (1.38 to 3.04$)$ & $<0.001$ \\
\hline $70-79$ & 5.30 (3.87 to 7.26$)$ & $<0.001$ & 3.25 (2.29 to 4.62$)$ & $<0.001$ \\
\hline 80 & 6.72 (4.92 to 9.18$)$ & $<0.001$ & 4.57 (3.27 to 6.40$)$ & $<0.001$ \\
\hline Male sex & 1.60 (1.27 to 2.03$)$ & $<0.001$ & 1.42 (1.12 to 1.80$)$ & 0.004 \\
\hline Cardiovascular diseases & 3.58 (2.80 to 4.58$)$ & $<0.001$ & 1.45 (1.08 to 1.94$)$ & 0.013 \\
\hline Respiratory diseases & 1.85 (1.36 to 2.52$)$ & $<0.001$ & & \\
\hline Gastrointestinal diseases & 2.01 (1.45 to 2.78$)$ & $<0.001$ & & \\
\hline Hepatobiliary diseases & 1.24 (0.76 to 2.02$)$ & 0.392 & & \\
\hline Renal diseases & 3.56 (2.62 to 4.84$)$ & $<0.001$ & 1.85 (1.33 to 2.57$)$ & $<0.001$ \\
\hline Genitourinary diseases & 2.20 (1.54 to 3.14$)$ & $<0.001$ & & \\
\hline \multicolumn{5}{|l|}{ Neurological diseases } \\
\hline Stroke & 2.49 (1.86 to 3.34$)$ & $<0.001$ & & \\
\hline Dementia & 2.98 (2.06 to 4.31$)$ & $<0.001$ & & \\
\hline Parkinson's disease & 4.17 (2.28 to 7.63$)$ & $<0.001$ & 1.95 (1.05 to 3.64$)$ & 0.035 \\
\hline Spine problems & 3.83 (1.58 to 9.27$)$ & 0.003 & & \\
\hline $\begin{array}{l}\text { Traumatic brain injuryrelated } \\
\text { disorders }\end{array}$ & 6.70 (1.66 to 26.97$)$ & 0.007 & & \\
\hline Other neurological diseases $†$ & 1.62 (0.96 to 2.73$)$ & 0.07 & & \\
\hline Diabetes mellitus & 2.82 (2.23 to 3.58$)$ & $<0.001$ & 1.61 (1.24 to 2.08$)$ & $<0.001$ \\
\hline Hyperlipidaemia & 1.65 (1.14 to 2.37$)$ & 0.008 & 1.94 (1.32 to 2.84$)$ & 0.001 \\
\hline Malignancies & 2.31 (1.59 to 3.37 ) & $<0.001$ & & \\
\hline $\begin{array}{l}\text { Coexisting infection other than } \\
\text { SARS }\end{array}$ & $1.78(1.34$ to 2.37$)$ & $<0.001$ & 1.49 (1.12 to 1.99$)$ & 0.007 \\
\hline
\end{tabular}

have more effective and stable binding to the ACE2 receptors in the target tissues. ACE2 receptors were abundant in lungs, as well as in the brain. Whether SARS-CoV-2 may be able to induce a greater damage in patients who had a stroke compared with that of SARS-CoV requires further investigation.

The strength of this study was that it was a territory-wide cohort study, which included all confirmed cases tested positive for SARS-CoV and SARS-CoV-2, regardless of whether they had symptoms. However, ascertainment bias from inaccurate or missing disease coding by the responsible physicians was possible under the busy working environment in public hospitals, which was a potential limitation of our study. We failed to assess the association of PD and COVID-19 mortality due to the very small number of patients with PD $(n=4)$ in our COVID-19 cohort and no one died in the studied period. The significant impact of dementia on COVID-19 mortality on univariate analysis was over-ridden by other comorbidities in the multivariable analysis model, which could also be accounted by the relatively small number of patients with dementia in our COVID-19 cohort $(\mathrm{N}=30$ with a prevalence of $0.95 \%$ only).

In conclusion, based on the current cohort study in Hong Kong, patients with neurological diseases, especially those who had a stroke and PD, were at high risk of mortality with COVID-19 and SARS infection. Protective strategies such as prioritised vaccination to these patients and their caregivers and facilitated use of telemedicine amid lockdown for these patients warranted urgent consideration, in order to reduce the morbidity and mortality of such a pandemic of COVID-19 with no foreseeable end in the near future. Florence Sin Ying Fan $\odot{ }^{1}$ Terry C F Yip,
Brian Yiu, ${ }^{2,3}$ Bonnie Lam, ${ }^{1,4}$ Lisa Au,

Alexander Yuk-Iun Lau $\odot{ }^{1,4}$ Bonaventure Ip $\odot$, 1

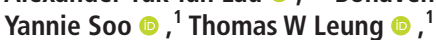
Timothy Li, ${ }^{6}$ Grace Lui, ${ }^{6}$ Grace L H Wong, ${ }^{2,3}$ Vincent Mok ${ }^{1,5}$

'Division of Neurology, Department of Medicine and Therapeutics, Prince of Wales Hospital, Faculty of Medicine, The Chinese University of Hong Kong, Shatin, Hong Kong

${ }^{2}$ Division of Gastroenterology and Hepatology, Department of Medicine and Therapeutics, Prince of Wales Hospital, Faculty of Medicine, The Chinese University of Hong Kong, Shatin, Hong Kong ${ }^{3}$ Medical Data Analytics Centre (MDAC), Faculty of Medicine, The Chinese University of Hong Kong, Shatin, Hong Kong

${ }^{4}$ Gerald Choa Neuroscience Centre, Lui Che Woo Institute of Innovative Medicine, Faculty of Medicine, The Chinese University of Hong Kong, Shatin, Hong Kong 
${ }^{5}$ Margaret KL Cheung Research Centre for Management of Parkinsonism, Faculty of Medicine, The Chinese University of Hong Kong, Shatin, Hong Kong ${ }^{6}$ Division of Infectious Diseases, Department of Medicine and Therapeutics, Prince of Wales Hospital, Faculty of Medicine, The Chinese University of Hong Kong, Shatin, Hong Kong

Correspondence to Professor Vincent Mok, Division of Neurology, Department of Medicine and Therapeutics, Prince of Wales Hospital, The Chinese University of Hong Kong Faculty of Medicine, Hong Kong, Hong Kong; vctmok@cuhk.edu.hk

Acknowledgements Assistance and support from Drs Anne YY Chan, Karen KY Ma, Howan Leung, Charlie Chan, Joseph Choi, Wai Ting Lui, Sze Ho Ma, and Vincent HL Ip from the Division of Neurology, Department of Medicine and Therapeutics, Prince of Wales Hospital, Faculty of Medicine, The Chinese University of Hong Kong were greatly appreciated.

Contributors FSYF and TCFY contributed equally. FSYF, TCFY, GLHW and VM designed the study. FSYF, $B Y, B L, L A, A Y L, B I, Y S, T W L, T L, G L, G L H W$ and VM collected data. All authors analysed and interpreted the data. FSYF and TCFY drafted the manuscript. AYL, GL, TL, TWL, GLHW and VM critically revised the manuscript. All authors approved of the final version of the manuscript. GLHW and VM supervised the study.

Funding The authors have not declared a specific grant for this research from any funding agency in the public, commercial or not-for-profit sectors.

Competing interests None declared.

Patient consent for publication Not required.

Ethics approval The study protocol was approved by the Joint Chinese University of Hong Kong-New Territories East Cluster Clinical Research Ethics Committee (reference number: 2020.074).

Provenance and peer review Not commissioned; externally peer reviewed.
Supplemental material This content has been supplied by the author(s). It has not been vetted by BMJ Publishing Group Limited (BMJ) and may not have been peer-reviewed. Any opinions or recommendations discussed are solely those of the author(s) and are not endorsed by BMJ. BMJ disclaims all liability and responsibility arising from any reliance placed on the content. Where the content includes any translated material, BMJ does not warrant the accuracy and reliability of the translations (including but not limited to local regulations, clinical guidelines, terminology, drug names and drug dosages), and is not responsible for any error and/or omissions arising from translation and adaptation or otherwise.

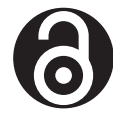

\section{OPEN ACCESS}

Open access This is an open access article distributed in accordance with the Creative Commons Attribution Non Commercial (CC BY-NC 4.0) license, which permits others to distribute, remix, adapt, build upon this work non-commercially, and license their derivative works on different terms, provided the original work is properly cited, appropriate credit is given, any changes made indicated, and the use is non-commercial. See: http://creativecommons.org/ licenses/by-nc/4.0/.

(c) Author(s) (or their employer(s)) 2021. Re-use permitted under CC BY-NC. No commercial re-use. See rights and permissions. Published by BMJ.

- Additional supplemental material is published online only. To view, please visit the journal online (http://dx.doi.org/10.1136/jnnp-2021-326286).

FSYF and TCFY contributed equally.

FSYF and TCFY are joint first authors.

\section{Check for updates}

To cite Fan FSY, Yip TCF, Yiu B, et al. J Neurol Neurosurg Psychiatry 2021;92:1356-1358.

Received 1 February 2021

Revised 9 April 2021

Accepted 12 April 2021

Published Online First 27 April 2021

J Neurol Neurosurg Psychiatry 2021:92:1356-1358. doi:10.1136/jnnp-2021-326286

\section{ORCID iDs}

Florence Sin Ying Fan http://orcid.org/0000-0002-93520421

Alexander Yuk-lun Lau http://orcid.org/0000-00025933-9290

Bonaventure Ip http://orcid.org/0000-0002-1619-4992

Yannie Soo http://orcid.org/0000-0002-3489-3201

Thomas W Leung http://orcid.org/0000-0001-81930709

\section{REFERENCES}

1 Williamson EJ, Walker AJ, Bhaskaran K, et al. Factors associated with COVID-19-related death using OpenSAFELY. Nature 2020;584:430-6.

2 Florez-Perdomo WA, Serrato-Vargas SA, BosqueVarela P, et al. Relationship between the history of cerebrovascular disease and mortality in COVID-19 patients: a systematic review and meta-analysis. Clin Neurol Neurosurg 2020;197:106183.

3 Fasano A, Elia AE, Dallocchio C, et al. Predictors of COVID-19 outcome in Parkinson's disease. Parkinsonism Relat Disord 2020;78:134-7.

4 Chan JWM, Ng CK, Chan YH, et al. Short term outcome and risk factors for adverse clinical outcomes in adults with severe acute respiratory syndrome (SARS). Thorax 2003;58:686-9.

5 Hu B, Guo H, Zhou P, et al. Characteristics of SARS-CoV-2 and COVID-19. Nat Rev Microbiol 2021;19:141-54. 